\title{
Performing arts medicine: A research model for South Africa
}

\author{
KDEVROOP
}

\begin{abstract}
Performing Arts Medicine has developed into a highly specialised field over the past three decades. The Performing Arts Medical Association (PAMA) has been the leading proponent of this unique and innovative field with ground-breaking research studies, symposia, conferences and journals dedicated specifically to the medical problems of performing artists. Similar to sports medicine, performing arts medicine caters specifically for the medical problems of performing artists including musicians and dancers. In South Africa there is a tremendous lack of knowledge of the field and unlike our international counterparts, we do not have specialised clinical settings that cater for the medical problems of performing artists. There is also a tremendous lack of research on performance-related medical problems of performing artists in South Africa. Accordingly the purpose of this paper is to present an overview of the field of performing arts medicine, highlight some of the significant findings from recent research studies and present a model for conducting research into the field of performing arts medicine. It is hoped that this research model will lead to increased research on the medical problems of performing artists in South Africa.
\end{abstract}

Keywords. Performing, arts, medicine, South Africa, musicians, research, music education.

\section{Introduction}

Over the past 30 years, Performing Arts Medicine has evolved into a highly specialised field and followed a developmental path similar to Sports Medicine. The origins of this unique interdisciplinary field can be traced back to the early 1970s by Dr Alice Branfonbrener (Branfonbrener, 1991; Tubiana \& Amadio, 2000), a pianist and medical practitioner who founded the Medical programme for Performing Artists at Northwestern University (Palac, 2008). In 1983 Dr Branfonbrener initiated the first research symposium in Aspen, Colorado, entitled the Medical Problems of Musicians (PAMA, 2013). This symposium eventually became known as the Medical Problems of Musicians and Dancers and led to the establishment of the Performing Arts Medical Association (PAMA) in 1988 (PAMA, 2013). Accordingly, PAMA became the first organisation dedicated to identifying the medical problems of performing artists, recommending appropriate treatment, fostering research and

Karendra Devroop is a Professor of Music at Unisa and NRF rated researcher. He is a widely published researcher with publications and conference presentations across North America, Europe, Asia and South Africa. kdevroop@unisa.ac.za 
promoting educational awareness internationally (Palac, 2008). To date, there are specialised clinics, research laboratories, educational institutions and a large body of medical practitioners, performers (music and dance), educators and administrators all dedicated to the promotion of Performing Arts Medicine across the world.

Over the past few decades, PAMA and several other international performing arts medical organisations (IFPAM, 2014; BAPAM, 2014) have heightened the awareness of the unique medical problems experienced by performing artists (Devroop \& Chesky, 2002). One of the leading organizations that spearheaded this drive through research and education has been the Texas Centre for Music and Medicine which was founded by Dr Kris Chesky. According to Palac (2008), in 2004 Dr Chesky and his colleagues at the Texas Centre for Music and Medicine hosted a ground-breaking conference entitled the Health Promotion in Schools of Music. This multidisciplinary conference which was supported by the Grammy foundation brought together professionals from the fields of music, medicine, audiology, engineering, education and several national organisations such as the National Endowment for the Arts, the Grammy Foundation and the National Association for Schools of Music together with several industry professionals (HPSM, 2004). The conference resulted in a clear delineation of the various categories of medical problems experienced by musicians, a white paper on recommendations for educational institutions that was adopted by the National Association for Schools of Music and international awareness of the field of performing arts medicine.

\section{The Medical Problems of Musicians}

Musicians may be at high risk for injury by virtue of their chosen profession (Dommerholt, 2009). These injuries include musculoskeletal pain, overuse injuries, entrapment, peripheral neuropathies and focal dystonia. Devroop \& Chesky (2002) also point out that the physical demands of performing a musical instrument coupled with long hours of practice could result in medical problems that impact performance and the overall health of musicians. In a series of studies conducted at the Texas Centre for Music and Medicine (Devroop \& Chesky, 2002; Chesky \& Devroop, 2003; Chesky, Devroop \& Ford, 2002; Chesky, Corns \& Devroop, 2000; Thrasher \& Chesky, 1998) researchers determined that some of the performancerelated medical problems of musicians included: site-specific musculoskeletal disorders, fatigue, stage fright, headache, dizziness, blackout, eye-strain, loss of lip, sleep disturbance and hearing loss.

At the Health Promotion in Schools of Music Conference (HPSM, 2004), the medical problems of musicians were placed into 4 overall categories: (1) neuromusculoskeletal health, (2) vocal health, (3) hearing health and (4) psychological health. Neuromusculoskeletal health deals primarily with physical injury to the human body and includes site-specific problems such as pain and/or injury to the fingers, hands, wrists, elbow, shoulder, neck, upper back and lower back. Focal and embouchure dystonia commonly referred to as a "computer hard drive crash” also fall into this category (Chesky, Devroop \& Ford, 2002). Vocal health includes medical problems typically associated with the voice and includes problems such as overuse of the larynx, vocal nodules and polyps, Gastroesophageal Reflux Disorder (the pooling of reflux in the vocal folds) and post-nasal drip (abrupt throat clearing which results in glottal attack on the vocal folds). Hearing health deals with noise-induced hearing loss while psychological health deals with issues such as stage fright, anxiety, depression, drug and alcohol abuse. 


\section{Ground-breaking Studies in Performing Arts Medicine}

There currently exists a large yet continuously expanding body of literature that addresses the medical problems of musicians. The bulk of these quantitative studies (descriptive, correlational and experimental) were conducted by researchers in the field of performing arts medicine on specific populations (Chesky, Corns \& Devroop, 2000; Fishbein et. al., 1988). However there also exists a large volume of case studies that were reported by medical practitioners in the medical journals. These case studies resulted due to medical practitioners treating musicians with performance-related injuries. Accordingly a large body of quantitative and qualitative studies has emerged. Due to the broad interdisciplinary nature of this filed, these studies are not confined to any one specific type of journal. While many studies can be found in performing arts medical journals such as Medical Problems of Performing Artists, most studies are published in journals in various fields including but not limited to medicine, psychology, sociology, education, teacher training, music and music education.

One of the first large scale studies ever conducted on performing artists was done by Martin Fishbein (Fishbein, 1988) on the population of musicians in the International Conference of Symphony and Orchestral Musicians (ICSOM). Over 4000 professional musicians from the 48 ICSOM orchestras were surveyed. A total of 2212, representing $50 \%$ of the musicians responded to the self-completed questionnaire. Results indicated that $82 \%$ of the orchestral musicians surveyed experienced a medical problem and $76 \%$ experienced a performancerelated medical problem that affected their playing. The study reports on site-specific performance related medical problems such as $52 \%$ of female clarinet players experiencing severe pain in the right hand, musician's use of beta-blockers and reports on nonmusculoskeletal problems such as fatigue, headache, dizziness and sleep disturbance.

The University of North Texas Musician Health Survey (UNT-MHS) was one of the first national surveys in the US to investigate the medical problems of musicians across genre (Chesky, Corns \& Devroop, 2000). The 4017 respondents included classical, jazz, hip-hop, country, pop, folk, Rhythm and Blues, Rap and church musicians. The responding group was diversified by age, gender, ethnicity, level (amateur to professional) and training (self-taught to university trained). Unlike the ICSOM study, the UNT-MHS also investigated the medical problems of non-classical musicians and sought to be more specific by identifying the performance-related medical problems of subgroups such as brass musicians, woodwind musicians, keyboardists, string and percussion musicians. Site-specific medical problems of subgroups such as the wrist problems of female clarinet players were investigated. This study resulted in one most comprehensive investigations into the medical problems of musicians and led to a large volume of follow-up studies being conducted internationally.

\section{Important Research Findings}

Musicians that expose themselves to performance-related medical problems could jeopardise their careers by inflicting injury that could negatively affect their performance and accordingly prevent them from reaching their career goals. One of the key outcomes of the Health Promotion in Schools of Music Conference (HPSM, 2004) was the adoption of an aggressive education and awareness agenda for all educational institutions. Following the conference, the National Association of Schools of Music (NASM) adopted the recommendation by the HPSM and now recommends that all university music schools provide educational coursework on the health and safety, including performance-related medical problems of 
musicians (NASM, 2014). It is critically important that musicians and other performing artists execute their craft in the safest possible manner.

While the literature contains a very large volume of research studies, those studies that could potentially impact large populations of musicians warrant further discussion. A survey of professional orchestral musicians found that approximately $76 \%$ experienced at least one performance-related medical problem severe enough to impact their playing (Fishbein, 1988). Bejjani (1996) indicated that prevalence rates for performance-related medical problems could be as high as $80 \%$. In a study of musicians at Brigham Young University, it was found that $87 \%$ of students surveyed indicated they experienced performance-related pain (Pratt, Jessop \& Niemann, 1992). The Australian orthopedic surgeon Hunter Fry was one of the first researchers to investigate the prevalence rates of medical problems among musicians. Some of his earliest studies were conducted on high school musicians and in 1987 he determined that $56 \%$ of high school music students experienced pain when playing (Fry, 1987). Clearly, musicians ranging from high school to university to professional experience medical problems related to music performance.

Additional neuromusculoskeletal problems identified in the literature include: respiratory problems (Sataloff, Spiegel \& Hawkshaw, 1990), glaucomatous damage as a result of high intraocular pressure (Schuman et al, 200), cardiac arrhythmias (Tucker, Faulkner \& Hovarth, 1971), injury to the obicularis oris muscle (Papsin, Maaske \& McGrail, 1996), lip pain (Brevig, 1991) and overuse syndrome (Fry, 1986). Borchers (1995) and his colleagues indicated that there may also be long-term and permanent injury to instrumental musicians. In a study on mouthpiece force, he determined that permanent tooth displacement had occurred in brass musicians as a result of excessive mouthpiece force (Borchers, Gebert \& Jung, 1995). Clearly, without timely intervention and educational awareness, musicians could be at risk for serious and potentially long-term neuromusculoskeletal injury.

Several researchers in music, medicine, psychology and audiology have conducted studies on the psychological and hearing health of musicians. Many of these studies focused on nonmusculoskeletal problems such as stage fright, anxiety, drug and alcohol abuse, beta-blocker use and depression. Key findings indicate that there were high prevalence rates for headache (46\%), blackout/dizziness (43\%) and eyestrain (41\%) in high pitched instruments such as trumpet and French horn (Devroop \& Chesky, 2002). According to Chesky \& Hipple (1999), the use of beta-blockers in preventing anxiety and stage fright by professional musicians was determined to be as high as $50 \%$. They also found that musician's perceptions of drug use among fellow musicians were estimated to be as high as $30 \%$. Hearing health and noise-induced hearing loss has garnered much attention in recent years. According to Henoch (2004), noise dose levels experienced by performing musicians exceeded the Occupational Safety and Health Administration (OSHA) guidelines thereby putting musicians at risk for hearing loss. Additionally, sound pressure levels in performing ensembles were found to be high enough to result in temporary threshold shift.

\section{The Need for Research on South African Musicians}

Much of the research on performing arts medicine has been conducted by researchers in primarily developed western countries including but not limited to the USA, Australia, Germany and the UK. Few if any studies were conducted by researchers in developing 
nations. A review of the literature indicates that no studies were conducted on South African musicians. In fact, at the recent Music and Well-being conference that was hosted at the School of Music at North-West University (NWU, 2013), there were no sessions on performing arts medicine except for one keynote address. There was also a general lack of knowledge and awareness of the field of performing arts medicine at the conference.

Other than a lack of baseline data on the medical problems of South African musicians, the need for such research is compounded when one considers that in South Africa, many professional musicians supplement their incomes with non-music jobs. Accordingly they are put at additional risk for injury by virtue of the demands of these non-musical jobs which could place additional stress on their bodies. The lack of specialised clinical settings designed to address the medical problems of performing artists coupled with the general lack of knowledge by medical practitioners on the biomechanics of instrumental music performance could result in inaccurate diagnosis of performance-related medical problems of musicians. Within South Africa, there is a need for research, education (at university level), general public awareness and clinical settings to cater for the needs of performance-related medical problems of performing artists.

\section{A Research Model for Performing Arts Medicine in South Africa}

Due to the unique nature of this field, it is proposed that South Africa follow a similar path of research and development of the field of performing arts medicine as practiced in the USA, Europe and Australia. The research model should include: (1) the establishment of research teams, (2) determination of prevalence rates of medical problems, (3) the identification of risk factors and, (4) education.

\section{Research Teams}

The nature of research in performing arts medicine is such that interdisciplinary collaboration is essential. It is very rare that a single individual will have all the necessary skills such as being a trained medical professional, a performing artist (music and/or dance) and experienced researcher. Although some individuals such as Dr. Alice Branfonbrener (who had all these skills) do exist, in most instances research in performing arts medicine is conducted by teams of professionals including but not limited to musicians, medical practitioners, engineers, psychologists and audiologists.

Research teams could be comprised of various individuals depending on the purpose of the study. In a study that investigated the biomechanics of trumpet performance (Devroop \& Chesky, 2002), the research team was comprised of a medical practitioner based at the medical school of the host university, a professor of mechanical engineering based at a partner university, a music educator from the host university and a professional trumpet player from the local symphony. The collective knowledge and training of these individuals ensured that the research study adequately addressed the purpose of the study. Similarly in a study on hearing loss on musicians, a team comprised of a professor of music education, an audiologist and two doctoral students (in music and audiology) successfully initiated and conducted the study. 


\section{Identification of Prevalence Rates}

Within South Africa, we have little to no baseline data on prevalence rates of performancerelated medical problems among musicians. This could be due to the lack of quantitative studies focusing on the performing arts in general. In order to identify specific problems and develop interventions, researchers would first need to obtain prevalence rates of medical problems across large populations. Accordingly studies similar to the ICSOM and UNTMHS would need to be undertaken on various populations of musicians within the country. Such studies would provide patterns of medical problems such as medical problems of vocalists and instrumentalists. These studies could target more specific groups such as brass musicians versus woodwind musicians, males versus females, amateur musicians versus professional musicians. Such studies would provide researchers, educators and performing musicians with sufficient baseline data upon which to conduct follow-up research.

The UNT-MHS initially surveyed a large population of musicians across genres, gender, age and performance level. Accordingly initial data enabled researchers to identify patterns across populations such as hearing loss being more prevalent among non-classical musicians than classical musicians and female classical musicians experiencing greater degrees of performance-related pain than their male counterparts. When patterns were identified such as medical problems of brass musicians being significantly higher than woodwind musicians, follow-up studies began focusing on more directed issues such as high brass musicians versus low brass musicians. In this manner, researchers were able to identify specific problems such as high pressure brass instrumentalists such as trumpet and French Horn experiencing more pain, dizziness and loss of lip than low brass instrumentalists such as trombone and tuba. Similarly, follow-up studies pointed to specific problems such as female clarinet players experiencing greater pain in the right hand than male clarinet players (Chesky, Kondraske \& Rubin, 2000).

Internationally, several studies have been conducted in order to determine prevalence rates of performance-related medical problems (Fry, 1987; Fishbein et. al., 1988). These studies have identified trends among musicians such as site-specific medical problems, hearing loss, drug and alcohol abuse and psychological problems such as stress, anxiety and depression among specific groups of musicians. Given the diversity of musical styles that exist in South Africa which includes but is not limited to classical music, jazz, Indian music, African music, pop, Kwaito and rap, there is a dire need to determine prevalence rates of medical problems among these musicians.

\section{Identification of Risk Factors}

The identification of risk factors is a critical step in the investigation of performance-related medical problems because they form the basis for intervention and preventative strategies. Risk factors could be due to a number of predisposing factors, some of which may be controlled and others not. These include but are not limited to: instrument type, instrument size, amount of practice and performance time, posture, performance literature, performance environment (jazz night club versus concert hall), performer's physical attributes and the biomechanics of performing on a specific instrument for example oboe performance requires a certain amount of force and inter-oral pressure in order to produce a sound while bassoon performance requires hyperextension of the fingers in the right hand. Specific instruments 
will require specific demands on the performer such as the physical weight of large instruments and force and pressure for higher pitched instruments.

One of the many findings from the UNT-MHS study (Chesky, Corns \& Devroop, 2000) was that brass performers, specifically high pitched instrumentalists such as trumpet and French horn experienced higher rates of embouchure pain, embouchure dystonia and nonmusculoskeletal problems such as headache and dizziness. Accordingly, they were at greater risk for injury. A follow-up study was done in order to determine the risk factors for trumpet performance. Two risk factors were identified: mouthpiece force and inter-oral pressure. The series of follow-up studies from this point forward set out to determine the amount of force and pressure utilised by amateur and professional trumpet players. Results indicated that some trumpet players were using excessive force in order to perform on their instruments. The excessive force was high enough to contribute to injury.

When risk factors such as these are identified and investigated, the focus should then shift to developing preventative strategies. While it is not always possible to change the biomechanics of performing on a specific instrument it is possible to identify ways of reducing the risk. In the above series of studies the challenge would be to identify ways of performing on the trumpet by minimising the amount of force exerted on the lip and reducing the amount of inter-oral pressure utilised by trumpet players. Reducing the impact of the risk factors on the performer will ultimately result in reducing the potential risk for injury, thereby enabling the performer to continue executing his/her art-form in a safe environment.

\section{Education}

Education is critically important to both performing artists and teachers. In fact it could be argued that short of an aggressive and sustained education campaign, the medical problems of performing artists will continue to permeate throughout our profession. If the cycle of performance-related medical problems is to be broken, then education becomes imperative. Several professional organizations such as the National Association for Music Education in the US have embraced the importance of educating musicians, teachers and students by mandating university coursework include information on performing arts medicine and musician health. While research findings and preventative strategies are filtering through to the youngest of musicians, much more still needs to be done in order to create greater awareness.

Responsibility also rests with instrument manufacturers. Some companies have embraced the findings from researchers and opted to include informational brochures in their instruments alerting musicians to the potential injuries that could result. Unfortunately only a small number of instrument manufacturers have opted to inform potential customers.

If awareness in South Africa is to be heightened then greater opportunities should be granted to researchers to present their findings at regional and national conferences. Researchers and educators should also be encouraged to present more workshops and symposia while also including readings in their university coursework. A sustained educational focus can only help our profession.

\section{Discussion}

The field of Performing Arts Medicine, although relatively young, is clearly an innovative TD, Special edition, 10(2), November 2014, pp. 47-56. 
and emerging field that is breaking new ground in the areas of research and performing arts. Over the past three decades there has been growing international interest and an expanding body of literature addressing the concerns of performing artists. This has been coupled with an increase in clinical settings in several countries that are dedicated to addressing the medical problems of performing artists. While the boundaries of research have been expanded, the concepts of interdisciplinary and collaborative research have become firmly entrenched in the field of performing arts medicine.

Within South Africa there is clearly a need to embrace this new and fascinating field. South African musicians, amateur and professional are faced with the same professional and environmental challenges as their international counterparts. It could be argued that South African musicians face additional challenges since many of them hold down additional nonmusic employment in order to supplement their incomes. Accordingly the physical demands of non-music related jobs could adversely affect the health of professional musicians. Amateur South African musicians also face social and psychological challenges that their international counterparts may not be exposed to, including lack of parental support due to high mortality rates as a result of HIV/AIDS, poverty, crime, drug abuse and high unemployment rates in the country. These social and psychological challenges could place undue burden on amateur musicians thereby impacting their health as performing artists.

University researchers are making tremendous strides in expanding the base of research fields in South Africa. Researchers are attempting to take on topics that include music therapy, music and cognition and music and health. There appears to be a growing number of published articles dealing with such topics in music and non-music related journals within the country. Several universities have also incorporated coursework at the undergraduate levels that attempts to expose students to fields such as music therapy. The major challenge facing future potential researchers is that the majority of South African music students are trained primarily in qualitative research methodology. Research coursework would need to embrace quantitative research in order for researchers to be fully equipped with the research tools to address research into fields such as performing arts medicine.

There is also a greater need in South Africa for more professional development opportunities. We currently have a very small number of conferences dedicated purely to music. Unlike our colleagues in the US and Europe, we do not have a major national music conference where sessions on performing arts medicine could be scheduled. Additionally, there are a very small number of music symposia that allows for the dissemination for research findings and sharing of knowledge among researchers and educators. In order to move our profession forward, greater effort needs to be made in order to bring our colleagues together for the mutual sharing of new and innovative fields such as performing arts medicine.

\section{Conclusion}

South Africa is well positioned to take a leading role in addressing and stimulating research into the field of performing arts medicine given its robust focus on research in general, its ability to drive this research agenda with partner countries on the African continent and its ability to work with its more economically and technologically developed partners in the BRICS group. Within the country, there already exists a solid platform upon which to build and explore this type of research given the large cohort of researchers in various fields 
including music, education, medicine, psychology, sociology, audiology and engineering. Many universities and research institutes already provide the necessary human and financial resources to foster and explore interdisciplinary and collaborative research. It is the motivation and drive of the researchers themselves that will ultimately lead to a spearheading of research in the field of performing arts medicine in South Africa.

\section{References}

BAPAM. 2014. British Association for Performing Arts Medicine. Retrieved on 28 July 2014 from http://www.bapam.org.uk/

Bejjani, F., Kaye, G. \& Benham, M. 1996. Musculoskeletal and neuromuscular conditions of instrumental musicians. Archives of Physical Medicine and Rehabilitation, 77:406-412.

Borchers, L., Gebert, M. \& Jung, T. 1995. Measurement of tooth displacements and mouthpiece forces during brass instrument playing. Medical Engineering and Physics, 17: 567-570.

Branfonbrenner, A. G. 1991. Performing Arts Medicine An Evolving Speciality. Music Educators Journal, 77(5): 37-41?

Brevig, P. 1991. Losing one's lip and other problems of the embouchure. Medical Problems of Performing Artists, 6: 105-107.

Chesky, K., Corns, J. \& Devroop, K. 2000. Population characteristics of an internet-based musician survey. In K Chesky, P Ellis and D Laufer (Eds.). Kolner Studien Zur Musik in Erziehung und Therapie (Music as a Medium: Applications and Interventions). Kleikamp Druck GmbH Lohn: Druck und Bindung.

Chesky, K. \& Devroop, K. 2003. The effects of college music instruction, gender and musician type on income from performing music. Medical Problems of Performing Artists, 18(2): 72-77.

Chesky, K., Devroop, K. \& Ford, J. 2002. Medical problems of brass instrumentalists: Prevalence rates for trumpet, trombone, French horn and low brass. Medical Problems of Performing Artists 17(2): 93-98.

Chesky, K. \& Hipple, J. 1999. Musicians perceptions of wide spread drug use among musicians. Medical Problems of Performing Artists, 14(4): 187-195.

Chesky, K., Kondraske G., \& Rubin, B. 2000. The Texas Center for Music and Medicine Explores the Biomechanics of Clarinet Performance. The Clarinet, 27(2), 34-36.

Devroop, K. \& Chesky, K. 2002. Comparison of biomechanical forces generated during trumpet performance in contrasting settings. Medical Problems of Performing Artists, 17(4): 149-154.

Dommerholt, J. 2009. Performing arts medicine - instrumentalist musicians part 1. Journal of Bodywork and Movement Therapies, 13(4): 311-119.

Fishbein, M., Middlestadt, S.E., Ottati, V., Straus, S. \& Ellis, A. 1988. Medical problems among ICSOM musicians: Overview of a national survey. Medical Problems of Performing Artists (3): 1-8.

Fry, H. 1986. Incidence of overuse syndrome in the symphony orchestra. Medical Problems 
of Performing Artists, 1: 51-55.

Fry, H. 1987. The prevalence of overuse (injury) in syndrome in Australian music schools. British Journal of Industrial Medicine, 44(1):35-40.

Henoch, M. 2004. Know the risk: Hearing loss and musicians. ITG Journal, 28(4): 54-55.

HPSM. 2004. The Health Promotion in Schools of Music Conference. Retrieved on 29 April 2014 from: http://goo.g1/oUDcXm

IFPAM. 2014. International Foundation for Performing Arts Medicine. Retrieved on 28 July 2014 from http://www.ifpam.org/

NASM. 2014. National Association of Schools of Music: Handbook 2013-2014. Retrieved on 6 May 2014 from: http://goo.gl/0bbfyh

NWU. 2013. Music and Well-being International Conference. Retrieved on 13 May 2014 from: http://www.musicwellbeing.co.za/

Palac, J. 2008. Promoting musical health, enhancing musical performance: Wellness for music students. Music Educators Journal, 94(3): 18-22.

PAMA. 2013. Maximizing performance: Artistry, implementation and empowerment. $\begin{array}{lllll}\text { Retrieved on } & 29 & \text { April } & 2014\end{array}$ http://www.artsmed.org/PAMAsymposium2013.pdf

Papsin, B., Maaske, L. \& McGrail, S. 1996. Orbicularis oris muscle injury in brass players. Laryngoscope, 106: 757-760.

Pratt, R.R., Jessop, S.G. \& Nieman, B.K. 1992. Performance-related disorders among music majors at Brigham Young University. International Journal of Arts Medicine 1(2): 7-20.

Sataloff, R. Spiegel, J. \& Hawkshaw, M. 1990. The effects of respiratory dysfunction on instrumentalists. Medical Problems of Performing Artists, 5: 94-97.

Schuman, J., Massicotte, E., Connolly, S., Hertzmark, M., Mukherji, B. \& Kunen, M. 2000. Increased intraocular pressure and visual field defects in high resistance wind instruments players. Opthalmology, 107(1): 127-133.

Thrasher, M. \& Chesky, K. 1998. Medical problems of clarinetists: Results from the UNT Musician Health Survey. Clarinet 25(4): 25-27.

Tubiana, R. \& Amadio, P.C. (eds.). 2000. Medical Problems of the Instrumentalist Musician. London: Martin Dunitz.

Tucker, A., Faulkner, M. \& Horvath, S. 1971.Electrocardiography and lung function in brass instrument players. Archives of Environmental Health, 23: 327-334. 